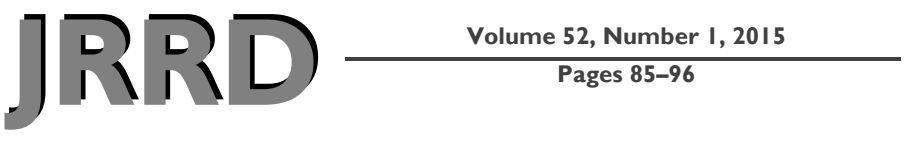

\title{
Respiratory responses to stimulation of abdominal and upper-thorax intercostal muscles using multiple Permaloc ${ }^{\circledR}$ electrodes
}

\author{
James S. Walter, PhD; ${ }^{1-2 *}$ Donald Thomas, MD; ${ }^{3-4}$ Scott Sayers, PhD; ${ }^{1-4}$ R. Anthony Perez-Tamayo, MD; ${ }^{3-4}$ \\ Timothy Crish; ${ }^{5}$ Sanjay Singh, PhD $^{1,6}$ \\ ${ }^{1}$ Research and Development Service, Edward Hines Jr., Department of Veterans Affairs (VA) Hospital, Hines, IL; \\ ${ }^{2}$ Department of Urology, Loyola University Stritch School of Medicine, Maywood, IL; ${ }^{3}$ Department of Cardiothoracic \\ Surgery, Edward Hines Jr., VA Hospital, Hines, $I L ;{ }^{4}$ Department of Cardiothoracic Surgery, Loyola University Stritch \\ School of Medicine, Maywood, IL; 5 Product Development \& Operations, Synapse Biomedical, Inc, Oberlin, OH; \\ ${ }^{6}$ East-West University, Chicago, IL
}

\begin{abstract}
Stimulation of abdominal and upper-thoracic muscles was studied with the long-term goal of improved respiratory care for spinal cord injury (SCI) patients. A 12-channel stimulator and multiple surface and implanted Permaloc electrodes were evaluated in five anesthetized canines. Abdominal stimulation with $100 \mathrm{~mA}$ using four bilateral sets of surface electrodes placed on the midaxillary line at the 7th through 13th intercostal spaces and with a closed airway at a large lung volume produced an expiratory tracheal pressure of $109+/-29 \mathrm{~cm}$ H2O ( $n=2$, mean $+/$ - standard error of the mean). Similar high pressures were induced with implanted electrodes at the same locations. Upper-thoracic stimulation with $40 \mathrm{~mA}$ and four sets of implanted electrodes ventral to the axilla induced inspiratory pressures of $-12+/-2 \mathrm{~cm} \mathrm{H} 2 \mathrm{O}(n=5)$. Combined extradiaphragmatic pacing with an open airway produced a tidal volume of $440+/-45 \mathrm{~mL}(n=4)$. The robust respiratory volumes and pressures suggest applications in SCI respiratory care.
\end{abstract}

Key words: abdominal muscles, cough, electrical stimulation, functional electrical stimulation, rehabilitation, respiration, respiratory distress, respiratory paralysis, spinal cord injury, upper-thoracic muscles.

\section{INTRODUCTION}

Most individuals with spinal cord injury (SCI) at upper cervical levels require ventilatory support. An alternative to mechanical ventilators is phrenic nerve stimulation, which has been shown to be helpful in these individuals [1-4]. Phrenic nerve stimulation can be delivered with mediastinal electrodes or diaphragmatic intramuscular hook electrodes. The intramuscular electrodes for this application (Peterson Electrodes, Case Western Reserve University [Cleveland, Ohio] or Permaloc ${ }^{\circledR}$ Electrodes Synapse Biomedical, Inc [Oberlin, Ohio]) are widely used [1]. One important limitation of phrenic nerve stimulation to generate tidal breathing is inward movement of the paralyzed upper rib cage; however, activation of upper-thoracic, external-intercostal, inspiratory muscles can ameliorate this effect [1]. Another limitation of phrenic nerve stimulation alone is the inability to recruit abdominal muscles [5-6], which are needed to produce cough. Abdominal contractions induce high expiratory velocity and flow rates for removal of respiratory secretions and are important in management of

\footnotetext{
Abbreviations: FRC = functional residual capacity, IV = intravenous, $\mathrm{pCO}_{2}=$ partial pressure of carbon dioxide, $\mathrm{rpm}=$ respirations per minute, $\mathrm{SCI}=$ spinal cord injury, SEM = standard error of the mean.

*Address all correspondence to James S. Walter, PhD; Edward Hines Jr., VA Hospital Research Service (Mail Stop 151), Roosevelt and First Ave, Hines, IL 60141; 708202-5805; fax: 708-202-2319. Email: James.Walter@va.gov http://dx.doi.org/10.1682/JRRD.2014.01.0018
} 
respiratory tract infections [1]. Abdominal muscle stimulation can also contribute to minute ventilation volumes as may be needed during respiratory distress; this contribution comes after the end of stimulation when elastic recoil of the chest and abdominal walls produces an inspiratory effect [1-3].

In patients [5-14] and laboratory animals [15-18], stimulation of extradiaphragmatic abdominal and upperthoracic respiratory muscles has been accomplished centrally with spinal epidural electrodes and peripherally with implanted and surface electrodes. Although large respiratory volumes were achieved from the extradiaphragmatic muscles with both of these approaches, they have not been extended to general SCI respiratory care. The primary limitation of epidural electrodes is the invasive surgery needed for implanting multiple electrodes to produce sufficient respiratory effects. Limitations with peripheral surface electrodes include the need for daily application of electrodes and wires, as well as respiratory responses that may be insufficient for effective cough [13-14].

Our laboratory has investigated the peripheral stimulation approach to extradiaphragmatic muscles using implanted Permaloc and related electrodes next to motor nerves. Respiratory responses in our prior studies were limited because of the use of too few electrodes, stimulating currents that were too low, and less than optimal electrode implant locations [19-22]. In the current study, improved methods to address each of these concerns were conducted and corresponding increases in respiratory responses were obtained.

\section{METHODS}

\section{Anesthesia, Respiratory Instrumentation, Apnea, and Stimulation Techniques}

Five adult male, short-hair canines weighing 15 to $25 \mathrm{~kg}$ (mean \pm standard error of the mean [SEM] $17.5 \pm$ $0.6 \mathrm{~kg}$ ) were obtained from commercial vendors (Oak Hill Genetics; Ewing, Illinois). Anesthesia was initiated with intravenous (IV) propofol (3-6 $\mathrm{mg} / \mathrm{kg}$ ) in the cephalic vein prior to intubation; next, isoflurane (1.5\%2.5\%) was delivered through an endotracheal tube in combination with continuous IV infusion of fentanyl (5-10 $\mu \mathrm{g} / \mathrm{kg} / \mathrm{h}$ ) [12]. Actual amounts or concentrations varied somewhat in each animal to maintain a deep level of surgical anesthesia. Animals were artificially venti- lated (Drager Anesthesia Ventilator; Louisville, Kentucky). Minute ventilation was titrated to maintain an end tidal partial pressure of carbon dioxide $\left(\mathrm{pCO}_{2}\right)$ of $35 \mathrm{~mm}$ Hg (Tidal Wave Capnograph/Osimeter, DRE Veterinary; Louisville, Kentucky). Atropine $(0.05 \mathrm{mg} / \mathrm{kg}$, intramuscular) was administered following anesthesia to reduce respiratory secretions. Body temperature was maintained at $38^{\circ} \mathrm{C}$ and IV isotonic saline ( $0.9 \%$, weight per volume) administered at a rate of $10 \mathrm{~mL} / \mathrm{kg} / \mathrm{h}$. After the respiratory protocols, animals were euthanized during deep anesthesia by IV administration of $50 \mathrm{cc}$ of Euthasol euthanasia solution (Virbac Corporation; Fort Worth, Texas). During autopsy, location of the intramuscular electrodes in the two sets of respiratory muscle groups was visually confirmed and documented by photography.

Animals were instrumented for respiratory monitoring: airway pressure was recorded at the end of the endotracheal tube and either isometric respiratory muscle contractions were recorded with a closed airway, the clamp being distal to the pressure recording site, or air flow and volume were recorded with an open airway [20-21]. Flow was monitored with a pneumotachometer (Model 300L, ADInstruments Inc; Colorado Springs, Colorado). The flow signal was integrated (LabChart, ADInstruments Inc) to determine inspired and expired volumes. Esophageal pressure was monitored with a small balloon-tipped tube made from a surgical glove finger that was sealed at the end of the tube with glue and thread. The balloon and tube were filled with water and advanced orally to the esophagus to a location just rostral to the diaphragm [21-22]. The same type of balloontipped tube was used for abdominal pressure recording, and the balloon was introduced anally and advanced 23 $\mathrm{cm}$ into the colon to lie caudal to the diaphragm [21-22]. A respiratory pneumobelt was used to record chest wall movement and was placed around the chest at the inferior edge of the sternum near the xiphoid process. A waterfilled tube that was open on the end and taped to the skin at the xiphoid was used as an indication of general body movements recorded as hydrostatic pressure changes. Shaking and jerking were recorded as spikes, and inspiration and expiration were indicated by gradual increases and decreases in baseline pressures, respectively. A Lead II electrocardiogram with small hook electrodes under the limbs was recorded to determine whether any heart arrhythmias were induced during stimulation. Blood pressure transducers (World Precision Instruments, Inc; Sarasota, Florida) and amplifiers (ADInstruments Inc) 
were used; recordings were displayed on a 16-channel recorder (ADInstruments Inc).

Three different types of stimulating electrodes were used for both extradiaphragmatic muscle groups. Surface electrodes (Conductive Black Rubber, $4 \times 4 \mathrm{~cm}$, Medtronic Inc; Minneapolis, Minnesota) required keeping the skin-electrode interface wet with isotonic saline for good electrical conduction. Suction electrodes (Synapse Biomedical Inc), which consisted of $5 \mathrm{~mm}$ diameter steel tubing that was insulated except at the tip, were held during testing by investigators. Permaloc electrodes were implanted directly into extradiaphragmatic respiratory muscles. Two modifications were made to these electrodes: first, polypropylene securing barbs were not installed so electrodes could be reused; second, distal ends of electrodes were permanently soldered to a lead for connection to the stimulator. Such modifications will not affect electrical properties of the Permaloc electrodes.

Electrical stimulations were delivered with a Permaloc 12-Channel Laboratory Pulse Generator (Synapse Biomedical Inc) controlled from a computer. Four channels were used in both abdominal and upper-intercostal muscle groups; an additional four channels were available for diaphragm pacing but were not used. Stimulation pulses were balanced biphasic and constant-current. Each phase of the biphasic pulse was a square wave that was $100 \mu$ s in duration, and there was a $100 \mu$ s delay between alternate waves. Current for each channel could be selected independently from 1 to $100 \mathrm{~mA}$. The maximal current of $100 \mathrm{~mA}$ was available in all five animals with implanted electrodes; however, the maximal current with surface electrodes was limited to only $50 \mathrm{~mA}$ per channel in the first three animals because of high electrode resistance. Following stimulator modifications, the maximal current of $100 \mathrm{~mA}$ was also available for surface electrodes in the last two animals. Available independently for both muscle groups was the stimulating frequency (10 to $50 \mathrm{~Hz}$ ) and current ramping. Ramping consists of linear increases in current from 0 to 100 percent over the preselected stimulation period. No ramping produced 100 percent of the selected current during the entire stimulation period. Available only for the stimulation channels usually used for the abdominal muscle group was staggering, which consisted of a 2 ms delay between stimulation of individual channels. Staggering for the upper thorax, however, could be accomplished by switching the wires on the outside of the stimulator. Single selections applying to both muscle groups included 6 to
20 respirations per minute (rpm) and stimulation period ( 0.5 to $2.5 \mathrm{~s}$ ). The stimulation periods were long enough for pressure or volume recordings to produce a peak plateau value longer than $150 \mu$ s.

Respiratory stimulation was conducted during a period of respiratory apnea following hyperventilation induced with $25 \mathrm{rpm}$, which drove the end-tidal $\mathrm{pCO}_{2}$ down to $27 \mathrm{~mm} \mathrm{Hg}$. Respiratory apnea followed the hyperpnea and lasted approximately 2 min when the animal was returned to the respirator. Stimulation records within $10 \mathrm{~s}$ of a spontaneous inspiration were excluded from analysis [20-21].

\section{Abdominal Muscle Stimulation with Closed Airway}

\section{Surface Electrodes}

Mapping and stimulation studies were conducted with four bilateral sets of surface electrodes, and peak isometric pressures as well as other respiratory measures were recorded. Maximal abdominal contractions are important to determine because they are needed for cough; therefore, high currents were tested. Only $50 \mathrm{~mA}$ per channel was available for testing in the first three animals, whereas $100 \mathrm{~mA}$ per channel was used in the last two animals (see explanation regarding stimulator in previous section). Other parameters for these high-current tests included $0.7 \mathrm{~s}$ stimulation period, simultaneous channels, and no current ramping. Lung volume has an effect on abdominal contractions; therefore, testing was conducted at both functional residual capacity (FRC) and FRC $+1,500 \mathrm{~mL}$. In the largest animal, FRC $+2,500 \mathrm{~mL}$ was used. The responses to stimulation at these two different lung volumes were similar and the results were pooled. Four locations were tested during these mapping tests, and the first three locations used electrodes in a straight line with equal separation between electrodes: (1) along the midaxillary line, a line that is parallel and approximately $10 \mathrm{~cm}$ ventral to the vertebra; the four bilateral electrodes were placed from the seventh rib interspace to the third lumbar area (Figure 1); (2) along a line $4 \mathrm{~cm}$ dorsal to the midaxillary line; (3) along the rostral edge of costal margin that separates the ribs from the abdomen, the line included three electrodes along the margin and the fourth dorsal to the margin; (4) a box arrangement was used with two electrodes ventral and two electrodes dorsal and placement of these electrodes was in the midlateral abdominal area. 


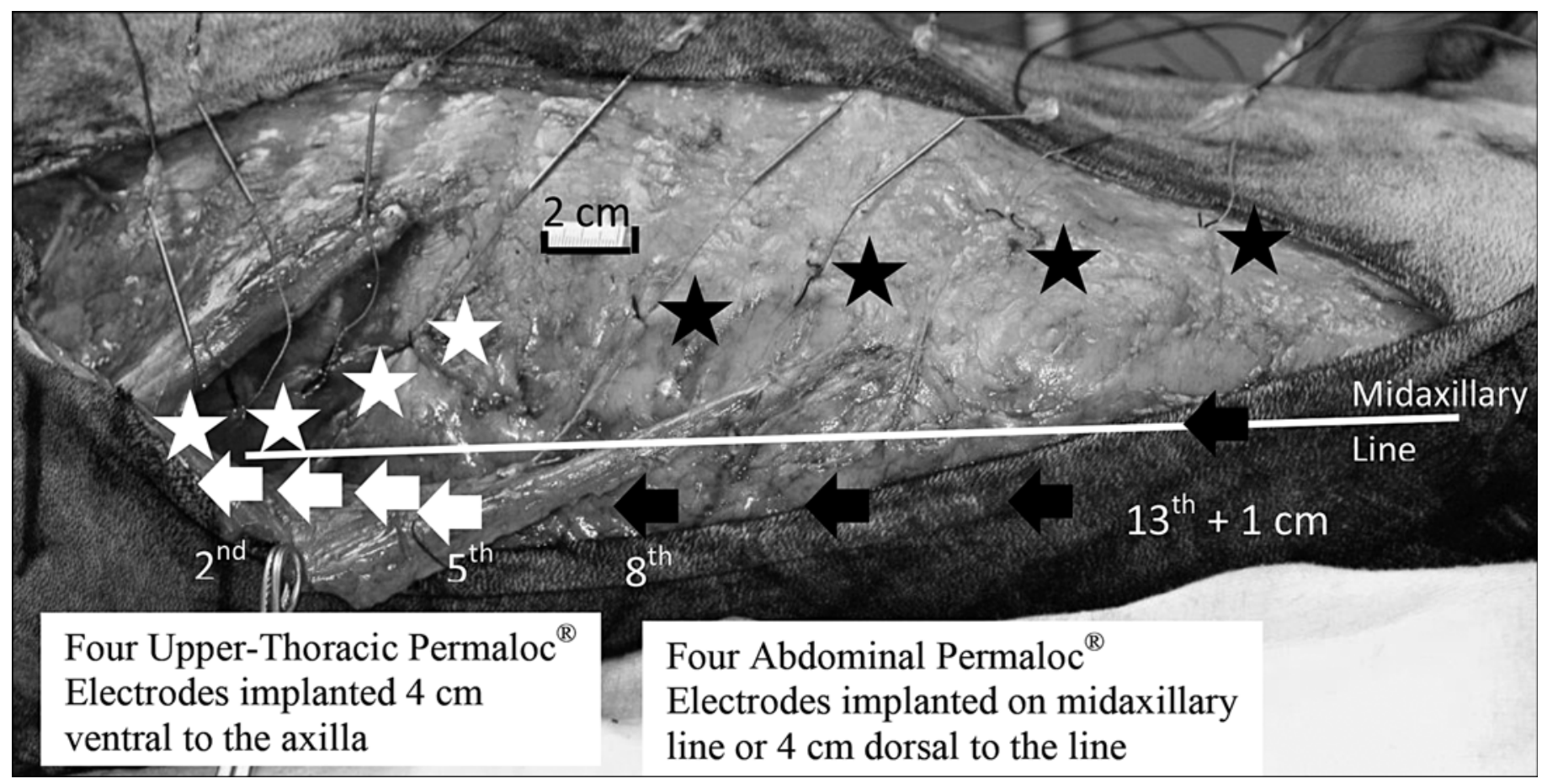

Figure 1.

Photograph of implanted Permaloc ${ }^{\circledR}$ electrodes in right lateral section of abdominal and upper-thoracic walls. Four bilateral sets of electrodes were implanted in abdominal and upper-intercostal muscle groups. Caudal abdominal electrodes (marked with dark arrows) were implanted on midaxillary line $1 \mathrm{~cm}$ caudal to 13th thoracic rib; remaining three electrodes were located at 8th through 11th intercostal spaces, $4 \mathrm{~cm}$ dorsal to midaxillary line. Four upper-thorax electrodes (marked with white arrows) are shown $4 \mathrm{~cm}$ ventral from axilla and at 2nd through 5th intercostal spaces. Leads of electrodes are marked where they enter muscles with sutures and by black stars for abdominal area and white stars for upper thoracic. Stimulating surfaces of electrodes were implanted approximately $1 \mathrm{~cm}$ deep in muscle and 4 to $6 \mathrm{~cm}$ dorsal to muscle entry site.

\section{Suction Electrodes}

Following abdominal incisions, further mapping was conducted with a single set of bilateral suction electrodes that were held on the muscles by the investigators (without suction) and were used to produce a more focused electrical field. For testing, $100 \mathrm{~mA}$ was used and individual intercostal spaces were tested on the midaxillary line and at dorsal and ventral locations from the line. These studies, however, were only conducted in three animals.

\section{Permaloc Electrodes}

Four bilateral sets of electrodes were implanted at locations identified during the mapping studies. Implants were at costal interspaces just caudal to the caudal edge of the rib near the intercostal nerve and approximately $1 \mathrm{~cm}$ deep (Figure 1). Below the 13th rib, electrodes were implanted at a similar depth so as not to enter the abdominal cavity. Testing following implantations used all four sets of implanted electrodes and included a complete current-response test with a maximal current of 100 $\mathrm{mA}$ per channel (400 mA for four channels). Further testing was conducted at $100 \mathrm{~mA}$ per channel to evaluate stimulation parameters including frequency, staggering of channels, and current ramping or no ramping.

\section{Upper-Intercostal Muscle Stimulation with Closed Airway}

Mapping tests in the upper-thorax followed the same protocols as for abdominal muscles. The four bilateral surface electrodes were tested from the first through fifth ribs that are important for inspiratory responses (Figure 1). Maximal stimulating currents were limited if there was more than slight forelimb movements. The single set 
of bilateral suction electrodes was tested at 40 to $75 \mathrm{~mA}$ to avoid forelimb movements induced with higher stimulating currents. Test locations were at intercostal spaces described for the surface electrodes and from the axilla to $4 \mathrm{~cm}$ ventral to the axilla. Four sets of bilateral Permaloc electrodes were then implanted at costal interspace locations identified as providing large inspiratory responses with no more than slight forelimb movement (Figure 1). Following implantations, testing was continued to assess effects of stimulating parameters.

\section{Respiratory Pacing with Open Airway}

Open airway testing was only conducted with the four sets of Permaloc electrodes that had been implanted in abdominal and thoracic respiratory muscles. Effective stimulation parameters that induced large respiratory volumes and flow rates were determined. Simultaneous channel stimulation was used for abdominal muscle stimulation, whereas only channel staggering was available in the upper thorax. Combined muscle stimulation was next conducted with the upper-thorax stimulated first and followed immediately with abdominal muscle stimulation [20-21]. A 5 min pacing test at 16 or 20 rpm was conducted using the effective stimulating parameters and combined muscle stimulation to assess muscle fatigue. Respiratory measures are presented as mean \pm SEM. Differences were compared with a paired Student $t$-test and were considered significant at $p \leq 0.05$ level.

\section{RESULTS}

\section{Abdominal Muscle Testing with Closed Airway}

\section{Surface Electrodes}

The first location tested with four bilateral sets of the bipolar electrodes was along the midaxillary line from $1 \mathrm{~cm}$ caudal to the 13th rib to the 7th rib interspace. Stimulation was conducted at $50 \mathrm{~Hz}$ for $0.7 \mathrm{~s}$ stimulation periods and without current ramping or channel staggering. In the first three animals, the maximal current available was $50 \mathrm{~mA}$ per channel and the peak abdominal and tracheal pressures were $<50 \mathrm{~cm} \mathrm{H}_{2} \mathrm{O}$ at FRC and FRC + 1,500 $\mathrm{mL}$. In the last two animals, $100 \mathrm{~mA}$ per channel (total 400 $\mathrm{mA}$ for four channels) was used, inducing a much greater respiratory response (Table 1). At FRC, stimulated peak abdominal pressure was $>90 \mathrm{~cm} \mathrm{H}_{2} \mathrm{O}$; however, this pressure was not effectively transmitted to the endotracheal tube, which showed pressures $<20 \mathrm{~cm} \mathrm{H}_{2} \mathrm{O}$. Upon increasing the lung volume to FRC $+1,500 \mathrm{~mL}$, the chest was observed to expand much more than the abdomen and baseline tracheal pressures increased more than abdominal pressures. Stimulation at the larger lung volume induced $>90 \mathrm{~cm} \mathrm{H}_{2} \mathrm{O}$ increases in pressure above baseline in both the abdominal and endotracheal tube, showing a

Table 1.

Increase in abdominal and tracheal pressures (in $\mathrm{cm} \mathrm{H}_{2} \mathrm{O}$ ) with stimulation of four bilateral sets of surface electrodes at $100 \mathrm{~mA}$ per set at four different abdominal locations; results shown at functional residual capacity (FRC) and FRC + 1,500 mL. ${ }^{*}$

\begin{tabular}{|c|c|c|c|}
\hline \multirow{2}{*}{ Location } & \multirow{2}{*}{$\begin{array}{c}\text { FRC } \\
\text { Stimulated }\end{array}$} & \multicolumn{2}{|c|}{ FRC + 1,500 mL } \\
\hline & & Baseline Increase & Stimulated $^{\dagger}$ \\
\hline \multicolumn{4}{|l|}{ On Midaxillary Line } \\
\hline Abdominal Pressure & $96 \pm 34$ & $10 \pm 0$ & $109 \pm 29$ \\
\hline Tracheal Pressure & $15 \pm 0$ & $32 \pm 4$ & $93 \pm 10$ \\
\hline \multicolumn{4}{|c|}{$4 \mathrm{~cm}$ Dorsal to Midaxillary Line } \\
\hline Abdominal Pressure & $88 \pm 23$ & $15 \pm 5$ & $103 \pm 23$ \\
\hline \multicolumn{4}{|l|}{ Rostral Side of Costal Margin } \\
\hline Abdominal Pressure & $91 \pm 23$ & $8 \pm 3$ & $111 \pm 29$ \\
\hline Tracheal Pressure & $19 \pm 6$ & $35 \pm 5$ & $69 \pm 21$ \\
\hline \multicolumn{4}{|l|}{ Mid-Lateral-Abdominal } \\
\hline Abdominal Pressure & $30 \pm 6$ & $13 \pm 8$ & $5 \pm 5$ \\
\hline
\end{tabular}


much better transmission of abdominal pressure to the trachea.

Testing at three other locations with the same stimulation conditions led to varied responses (Table 1). With the line of electrodes $4 \mathrm{~cm}$ dorsal to the midaxillary line and a line along the rostral side of the costal margin, abdominal pressures $>90 \mathrm{cmH}_{2} \mathrm{O}$ continued to be induced; however, endotracheal tube pressures were $<90 \mathrm{~cm} \mathrm{H}_{2} \mathrm{O}$, showing some reduced transmission of abdominal pressures to the trachea. The final location, the midlateral abdominal area, produced much lower abdominal and endotracheal tube pressures.

\section{Suction Electrodes}

Further mapping was conducted with the single set of bilateral suction electrodes and tested at $100 \mathrm{~mA}$ stimulating currents. As shown by the respiratory pressure tracings in Figure 2, abdominal and tracheal expiratory pressures were low when stimulation was applied at FRC; however, at FRC $+1,500 \mathrm{~mL}$, higher abdominal and endotracheal tube pressures of 15 to $30 \mathrm{~cm} \mathrm{H}_{2} \mathrm{O}$ were induced both along the midaxillary line from $6 \mathrm{~cm}$ caudal to the costal margin to the sixth thoracic interspace and along a dorsal-ventral line at the eighth thoracic interspace. Stimulations 4 and $6 \mathrm{~cm}$ dorsal to the midaxillary line at the eighth interspace induced the highest peak endotracheal tube pressure of $30 \mathrm{~cm} \mathrm{H}_{2} \mathrm{O}$. Similar observations were made in all three animals tested and suggest that electrodes should be implanted along the midaxial line or just dorsal to it.

Further testing $6 \mathrm{~cm}$ caudal to the 13th rib also produced high expiratory responses but also induced unwanted lower-limb movements, which could be avoided by stimulating more rostrally where peak expiratory pressures could still be maintained. At the rostral end of testing sites, the sixth rib interspace, abdominal contractions could be induced but forelimb movement occurred; these movements were avoided by stimulating caudal to the sixth rib interspace. These results suggest the rostral-caudal regions where electrodes should be implanted.

\section{Permaloc Electrodes}

Using identified effective stimulation sites, four bilateral sets of Permaloc electrodes were implanted. In the first two animals, these electrodes were inserted along the midaxillary line, including $1 \mathrm{~cm}$ caudal to the 13th rib and 12th, 10th, and 8th interspaces; in the last three ani-

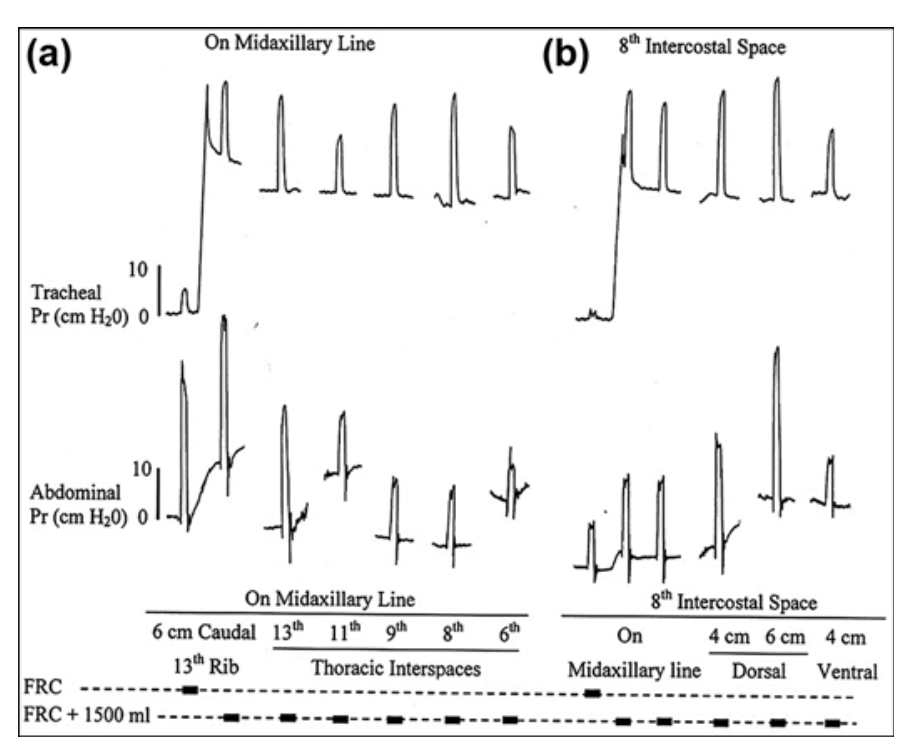

Figure 2.

Recordings of tracheal pressure and abdominal pressure $(\mathrm{Pr})$ at both functional residual capacity (FRC) and FRC $+1,500 \mathrm{~mL}$ during abdominal muscle stimulation using single set of bilateral suction electrodes at different locations. Test sites are (a) along midaxillary line at thoracic interspaces and (b) in dorsal and ventral directions at 8th intercostal space, with distances shown from midaxillary line. Stimulations at $50 \mathrm{~Hz}$ and $100 \mathrm{~mA}$ for $0.7 \mathrm{~s}$ stimulation period with no current ramping are marked with dark line at base of recording. (a) 10 to $30 \mathrm{~cm} \mathrm{H}_{2} \mathrm{O}$ tracheal pressures were recorded at locations from $6 \mathrm{~cm}$ caudal to 13th rib to 6 th intercostal space. (b) Highest induced tracheal pressures were recorded at 4 and $6 \mathrm{~cm}$ dorsal to midaxillary line. Larger pressure responses were also recorded when stimulating at FRC $+1,500 \mathrm{~mL}$ than at FRC. Baseline drifts in abdominal pressure recorded with colonic balloon represent peristaltic colonic activity. Pressure recordings with closed airway.

mals, the implantations were at the same interspaces but the three rostral electrodes were implanted $4 \mathrm{~cm}$ dorsal to the midaxillary line (Figure 1). Respiratory responses from the two different implant locations were similar; therefore, the data were pooled.

Stimulation conditions for the implanted abdominal electrodes included $50 \mathrm{~Hz}$ stimulating frequency, no channel staggering, and a lung volume of FRC $+1,500 \mathrm{~mL}$ (Table 2). Current-response tests showed that increases in current from 25 to $100 \mathrm{~mA}$ induced corresponding increases in peak abdominal and endotracheal tube 
Table 2.

Abdominal and tracheal peak pressure (in $\mathrm{cm}_{2} \mathrm{O}$ ) during stimulation with four bilateral Permaloc ${ }^{\circledR}$ electrodes implanted at increasing stimulating currents.

\begin{tabular}{lcccc}
\hline \multirow{2}{*}{ Muscle } & \multicolumn{5}{c}{ Stimulating Current (mA) } \\
\cline { 2 - 5 } & $\mathbf{2 5}$ & $\mathbf{5 0}$ & $\mathbf{7 5}$ & $\mathbf{1 0 0}$ \\
\hline Abdominal $^{*}$ & & & & \\
Abdominal Pressure $_{\text {Tracheal Pressure }}$ & $17 \pm 3$ & $44 \pm 11$ & $72 \pm 1$ & $94 \pm 10(n=3)$ \\
& $26 \pm 2$ & $64 \pm 17$ & $81 \pm 12$ & $91 \pm 12(n=4)$
\end{tabular}

\begin{tabular}{crrrc} 
& $\mathbf{1 0}$ & $\mathbf{2 0}$ & $\mathbf{3 0}$ & $\mathbf{4 0}$ \\
\cline { 2 - 5 } Upper-Thorax Intercostal $^{\dagger}$ & & & & \\
Tracheal Pressure & $-7 \pm 2$ & $-9 \pm 2$ & $-10 \pm 2$ & $-12 \pm 2(n=5)$
\end{tabular}

*Abdominal muscle stimulation at $100 \mathrm{~mA}, 50 \mathrm{~Hz}, 0.7 \mathrm{~s}$ stimulation period with no ramping and no staggering of channels. Pressures recorded during isometric contractions against closed airway. See main text and Figure 1 for electrode locations; stimulation at functional residual capacity (FRC) $+1,500 \mathrm{~mL}$.

${ }^{\dagger}$ Upper-intercostal muscle stimulation at $40 \mathrm{~mA}, 50 \mathrm{~Hz}, 0.7 \mathrm{~s}$ stimulation period with no ramping or staggering of channels. See Figure 2 for electrode locations; stimulation at FRC.

pressures. Surprisingly, at these lower currents, endotracheal tube pressures were higher on average than abdominal pressures. At $100 \mathrm{~mA}$, the highest current available per stimulating channel, $>90 \mathrm{~cm} \mathrm{H}_{2} \mathrm{O}$ abdominal and endotracheal tube pressure occurred. Three additional tests were conducted at the $100 \mathrm{~mA}$ stimulating current. Stimulation at $20 \mathrm{~Hz}$ only induced a peak endotracheal tube pressure $61 \pm 5$ percent as high as at $50 \mathrm{~Hz}$ stimulation $(n=4, p \leq$ $0.05)$. Staggering of the stimulating channels only induced a pressure $54 \pm 3$ percent as high as simultaneous channel stimulation ( $n=5, p \leq 0.05$ ). Current ramping did not reduce peak endotracheal tube pressures compared with protocols without current ramping. With ramping, however, the peak pressure only occurred at the end of the stimulation period, compared with a sustained, plateau, peak pressure that occurred during stimulation without ramping. More graded muscle contractions occurred with ramping. Two side effects of stimulation observed during these and related tests that included the $100 \mathrm{~mA}$ per channel stimulation (400 mA for four channels) and abdominal pressures $>80 \mathrm{~cm} \mathrm{H}_{2} \mathrm{O}$ were urination $(n=5)$ and defecation $(n=1)$.

\section{Upper-Intercostal Muscle Testing with Closed Airway}

\section{Surface Electrodes}

Stimulation tests were conducted at FRC and with four surface electrodes placed over the upper-thoracic muscles from the axilla to near the sternum and from the first to the fifth interspaces. Stimulation at $50 \mathrm{~Hz}$ and
$50 \mathrm{~mA}$ (total $200 \mathrm{~mA}$ for four channels) induced peak inspiratory pressures of only $-6 \pm 1 \mathrm{~cm} \mathrm{H}_{2} \mathrm{O}(n=4)$. Higher stimulating currents induced excessive forelimb movement, precluding their use. The four surface electrodes completely covered the upper-thorax area of interest; thus, no other locations were tested.

\section{Suction Electrodes}

Mapping with suction electrodes was conducted at the same interspaces as for the surface electrodes with 40 to $75 \mathrm{~mA}$ stimulating current. At the first thoracic interspace, high negative inspiratory pressures were induced, but there was forelimb contraction, particularly near the axilla, precluding further testing at these locations. At the second and third intercostal spaces, maximal inspiratory pressures of -6 to $-12 \mathrm{~cm} \mathrm{H}_{2} \mathrm{O}$ were induced; however, moderate leg contractions did occur near the axilla. Inspiratory responses without the forelimb contractions were obtained at 1 to $4 \mathrm{~cm}$ dorsal to the axilla. At the fourth and fifth interspaces, reduced inspiratory pressures of -5 and $-6 \mathrm{~cm} \mathrm{H}_{2} \mathrm{O}$ were recorded. The sixth interspace did not produce an inspiratory effect.

\section{Permaloc Electrodes}

Four bilateral sets of Permaloc electrodes were then implanted $4 \mathrm{~cm}$ ventral to the axilla at the second through fifth costal interspaces approximately $1 \mathrm{~cm}$ deep into the thoracic muscles (Figure 1). Current-response testing demonstrated that the highest inspiratory pressures occurred at $40 \mathrm{~mA}$, resulting in $-12 \mathrm{~cm} \mathrm{H}_{2} \mathrm{O}$ inspiratory pressure with only slight forelimb movement, slight to moderate in one animal (Table 2). Abdominal pressure changes during this stimulation were small. A higher stimulating current of $60 \mathrm{~mA}$ evaluated in two animals induced high inspiratory pressures of -30 to $-40 \mathrm{~cm}$ $\mathrm{H}_{2} \mathrm{O}$; however, strong forelimb movements occurred. Based on electrocardiogram recording, no heart arrhythmias were induced during any stimulation test.

Two additional tests were conducted with $40 \mathrm{~mA}$ stimulation current. Stimulation at $20 \mathrm{~Hz}$ was $89 \pm 9$ percent $(n=5)$ as effective as at $50 \mathrm{~Hz}$ in inducing peak inspiratory endotracheal tube pressures. Current ramping induced equivalent maximal pressures compared with stimulation without ramping; however, ramping produced much more even muscle contractions. 


\section{Respiratory Pacing with Open Airway}

The four bilateral sets of implanted Permaloc electrodes in both respiratory muscles were used in respiratory pacing studies measuring airway volume and flow. Effective stimulation parameters were determined in both individual muscle groups to produce the highest respiratory responses without more than slight limb movements. No ramping of the stimulating current or staggering of the stimulation channels was used. For abdominal muscle stimulation, $50 \mathrm{~Hz}$ was most effective in all four animals. Higher volumes in three animals were induced with 100 $\mathrm{mA}$, whereas in the fourth animal expiratory volumes were increased using only $75 \mathrm{~mA}$. Complete expiration occurred at $0.5 \mathrm{~s}$, as seen in the plateau of the expiratory volume recording; however, a longer period of $1.3 \mathrm{~s}$ was included as the effective period because it had to apply to both muscle groups and the upper thorax required the period of $1.3 \mathrm{~s}$ for a complete inspiration. For the upper thorax, $50 \mathrm{~Hz}$ stimulation frequency induced larger respiratory responses in three animals, whereas $20 \mathrm{~Hz}$ induced the larger responses in two animals. In three animals, 40 $\mathrm{mA}$ current was used and in one animal, $30 \mathrm{~mA}$ when greater inspiratory responses were observed.

Respiratory records using the effective stimulating parameters are shown in Figure 3, where combined muscle stimulation is also included. Both individual muscle stimulations recorded the low endotracheal tube and esophageal pressures that are typical of stimulation responses with an open airway. For abdominal muscle stimulation alone, abdominal pressures are high and pneumobelt records show large upper-chest expansions during stimulation. During upper-thorax stimulation alone, abdominal pressures were low, but a large upperchest expansion occurred. Flow and volume records reflect expiratory and inspiratory effects that were greater for stimulation of the upper-thorax than for abdominal muscles. Body movements recorded with the hydrostatic tube located at the level of the mediastinum showed uneven body movement (jerking) during stimulation, revealed as wide black lines in Figure 3; elevation of the mediastinum is shown by increases in baseline pressures. The largest respiratory volumes and flows, shown in Figure 3, occurred during combined upper-intercostal stimulation followed immediately by abdominal stimulation. This large expiratory volume was measured from the peak of the upper-thorax inspiratory volume to the trough of abdominal muscle expiration. Such expiratory effort is

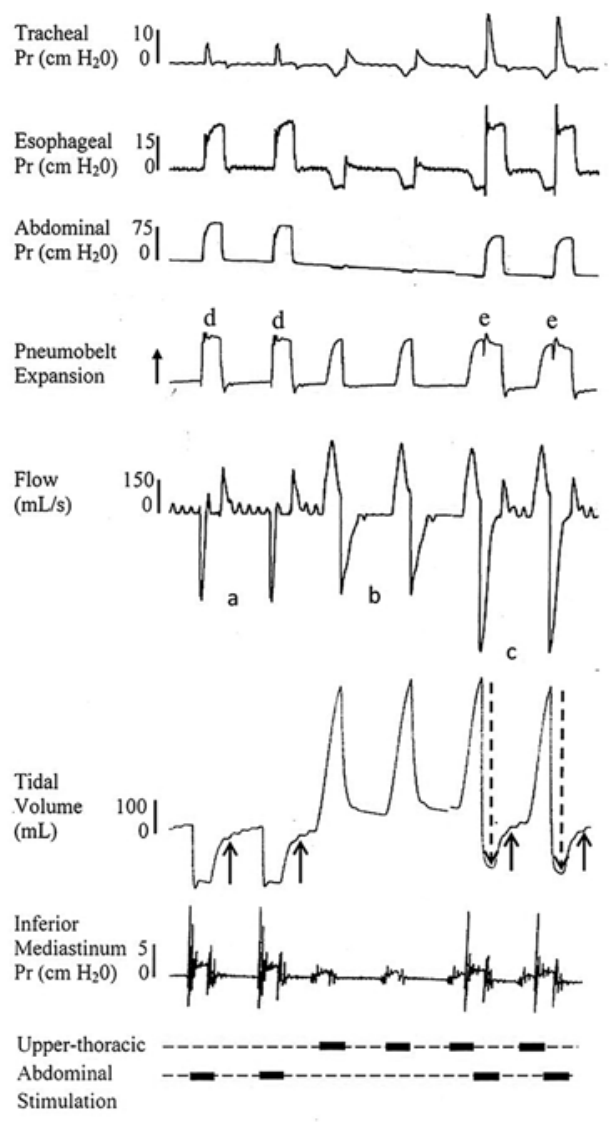

Figure 3.

Tracings of air flow, tidal volume, and other respiratory measures during stimulation with Permaloc ${ }^{\circledR}$ electrodes in abdominal (100 mA) and upper-intercostal (40 mA) muscles alone and then in combination with open airway. (a) Peak expiratory flow for abdominal stimulation alone was relatively low and limited by expansion of chest (pneumobelt (d)). (b) Upper-thorax stimulation alone induced relatively low expiratory flow after end of stimulation. (c) In contrast, combined muscle stimulation induced high expiratory flow rate at transition from upper-thorax to abdominal wall stimulation that was not limited by expansion of chest (pneumobelt (e)). Tidal volume was also increased by combined muscle stimulation. Stimulations were with four bilateral sets of Permaloc electrodes in both abdominal and upper-intercostal muscle groups at $50 \mathrm{~Hz}$ for $1.3 \mathrm{~s}$ stimulation periods (marked with dark line at base of recording). Solid arrows in tidal volume records show elastic recoil of lung volumes to functional residual capacity (FRC) following forced expiration produced by stimulation of abdominal muscles; dashed arrows indicate tidal volume measured from the peak of inspired volume to the largest expired volume during combined muscle stimulation. Dark bars at bottom of recording indicate stimulation of extradiaphragmatic muscles. Pneumobelt upward arrow direction indicates upper-thorax expansion. 
also associated with higher flow rates than occurred with stimulation of individual muscle groups. Pneumobelt recordings of the thorax during this combined stimulation showed that the chest expansions during upper-thorax muscle stimulation were maintained during abdominal stimulation.

The average inspiratory peak volume using effective upper-thoracic stimulation was $310 \pm 41 \mathrm{~mL}(n=4)$. The average expired peak volume for abdominal stimulation alone was $153 \pm 20 \mathrm{~mL}$. Combined muscle stimulation induced an expiratory effort of $440 \pm 45 \mathrm{~mL}$, which is significantly greater than with either individual muscle group ( $n=4, p \leq 0.05$ ). The peak expiratory flow during abdominal muscle stimulation alone was $500 \pm 100 \mathrm{~mL} / \mathrm{s}$, which was significantly lower than that for combined respiratory muscle stimulation, which amounted to $900 \pm$ $100 \mathrm{~mL} / \mathrm{s}(n=4, p \leq 0.05)$.

The 5 min respiratory pacing test used combined muscle stimulation. In three animals, $16 \mathrm{rpm}$ was used and in one animal, $20 \mathrm{rpm}$; because similar responses occurred at the two different rates, the results were pooled. The tidal volume at the start of pacing was $443 \pm$ $44 \mathrm{~mL}$, and at the end of the $5 \mathrm{~min}$ pacing, the tidal volume was $411 \pm 24 \mathrm{~mL}(n=4)$, demonstrating that the tidal volume was well maintained.

\section{DISCUSSION}

\section{Abdominal Muscle Stimulation}

This is the first study, to our knowledge, to stimulate abdominal muscles with four bilateral sets of surface and implanted electrodes along the midaxial line and to use conditions of simultaneous channel stimulation with a high current of $100 \mathrm{~mA}$ per channel or $400 \mathrm{~mA}$ total for four channels. Other important study conditions included pressure recording with a closed airway and a lung volume of FRC $+1,500 \mathrm{~mL}$ or flow and volume with an open airway, balanced biphasic stimulating pulses, bipolar electrodes across the body, and $50 \mathrm{~Hz}$ stimulation frequency. Large expiratory responses were induced with both the surface and implanted electrodes and were much larger than those obtained in our previous studies using fewer electrodes implanted in midlateral abdominal areas and using lower stimulating currents [19-22].

In anesthetized canines, epidural electrodes on the dorsal side of the lower-thoracic spinal cord elicited strong abdominal muscle contractions with an average exhaled volume of $218 \mathrm{~mL}$ [15]. Clinical studies with electrodes on the abdominal surface and on the ventral side of the spinal cord have produced exhaled volumes greater than 1 L [5-9]. DiMarco et al. attributed the large exhaled volumes during ventral spinal cord stimulation to spread of the electric field to multiple spinal levels and recruitment of multiple abdominal muscles [7]. Lin et al. noted in canines that stimulation of multiple spinal levels is important to enhance respiratory volumes [18]. Lee et al. observed large expiratory volumes suitable for cough production using surface electrodes over the costal margin in one SCI patient; they stated that the caudal, dorsallateral area of the abdominal wall was a particularly important stimulation site to generate high expiratory volumes [11]. Multiple mechanisms probably contributed to the large expiratory volumes reported in this study including those suggested by DiMarco et al. [7], Lin et al. [18], and Lee et al. [11].

\section{Upper-Intercostal Muscle Stimulation}

Multiple implanted Permaloc electrodes in the upperthorax were more effective than surface electrodes in generating inspiratory pressures because surface electrodes were limited by more spread of current to forelimb muscles. The inspiratory responses with implanted electrodes are significantly larger than those obtained in our previous studies using only two bilateral sets of implanted electrodes [19-22]. Inspiratory volumes in this study are similar to those cited by DiMarco et al. using epidural electrodes on the spinal cord [5,7,15-17]. Again, these investigators attributed the large inspiratory volumes to spread of the electrical field to several thoracic levels along the spinal cord and, therefore, stimulation of multiple muscle groups. We stimulated four intercostal spaces in each hemithorax, similar to DiMarco et al. $[5,15]$, who recruited the second to fifth intercostal spaces using the more invasive technique of spinal cord stimulation.

\section{Respiratory Pacing}

Combined accessory respiratory muscle stimulation with an open airway produced nearly 100 percent greater flow and volume responses than could be obtained with individual muscle stimulation. Thus, combined muscle stimulation is important for obtaining large respiratory responses needed for cough production. The peak flow rate recorded in this study of $0.9 \mathrm{~L} / \mathrm{s}$ is well below the effective flow rate needed by patients for cough of $4.5 \mathrm{~L} / \mathrm{s}$ 
[5,15]; however, this difference can be explained, in part, by the smaller size of the dog abdominal cavity compared with humans [21]. Importantly, similar stimulation induced ventilatory responses in anesthetized canines as those reported here have been translated to human ventilation and cough production [15,17-18]. Finally, the 5 min respiratory pacing results with combined muscle stimulation showed that large tidal volumes can be maintained, which is important for chronic ventilation applications.

\section{Limits of Techniques}

Mapping with surface and suction electrodes to locate sites for implanted electrodes was limited because stimulation of overlying muscles occurred; alternatively, mapping with small intramuscular electrodes would be more accurate. For abdominal muscles, four bilateral sets of implanted electrodes may have been insufficient because only every other rib interspace could be stimulated; thus, more electrode implants may be more effective. Further, the maximal current of $100 \mathrm{~mA}$ per channel may have been too low; current-response curves showed increased responses up to this maximal current, indicating that higher currents would have resulted in even greater responses (Table 2). Stimulation of abdominal muscles in some cases was associated with poor transmission of abdominal pressures to the trachea and insufficient flow rates needed for respiration and cough (Table 1, Figures 2 and 3). Limited tracheal pressures were associated with expansion of the upper chest as shown in the pneumobelt recording during abdominal stimulation (Figure 3). In contrast, with combined muscle stimulation, activation of abdominal muscles started with an expanded upper chest at the end of upper-thorax stimulation, and thus, a greater abdominal expiratory effect was induced (Figure 3). In other cases of abdominal stimulation alone, abdominal pressures were well transmitted to the trachea, which occurred with use of the full set of four bilateral electrodes at effective stimulation sites. This stimulation probably activated abdominal oblique muscles that can reduce upper-chest expansion. Glottis closure is an important part of cough production with abdominal contractions, but glottis closure was not modeled. Cough begins with a forced expiration against a closed glottis to build up tracheal pressures. With partial opening of the glottis a very high air-velocity and flow occurs, and the force generated dislodges and moves mucus out of the airways. Individuals with SCI can be trained for glottal maneuvers with an external light signal to indicate the onset and duration of closure; such maneuvers should be included in this Permaloc system [10-11].

For the upper thorax, four surface electrodes at a maximum of $50 \mathrm{~mA}$ produced unwanted forelimb movement and might be improved by using fewer electrodes at higher stimulating current to better focus the electrical field. With implanted Permaloc electrodes in the upper thorax, $20 \mathrm{~Hz}$ stimulation frequency was only slightly less effective in inducing a respiratory response than $50 \mathrm{~Hz}$; thus, further frequency-response testing is warranted to determine an optimal stimulating frequency. The stimulator program we used did not have the option of simultaneous channel stimulation for the upper thorax, only staggered channel stimulation, for combined muscle stimulation protocols; future software programs should include this option. The ability to independently set the stimulation periods for the abdominal and upper-intercostal muscles would also have been useful to further refine our stimulation parameters.

\section{CONCLUSIONS AND FUTURE DIRECTIONS}

Our respiratory stimulation system included the Permaloc 12-Channel Laboratory Pulse Generator and surface and Permaloc intramuscular electrodes for stimulation of accessory respiratory abdominal and upper-thoracic muscles. The large respiratory responses induced warrant further investigation for application in SCI respiratory care. Although the primary application for this system will be in conjunction with diaphragmatic pacing, applications independent of diaphragmatic pacing should be considered further. Clinical testing with surface electrodes could be conducted because this noninvasive approach has minimal risk or regulatory restrictions and further testing may be more effectively conducted in patients rather than in animal models. Further studies with implanted electrodes, however, should address the limitation noted in this current study. In addition, measurement of oxygen utilization during stimulation of large extradiaphragmatic respiratory muscles should be conducted to determine how electrically stimulated contraction of these muscles affects oxygen utilization. Finally, current testing with Permaloc electrodes will facilitate technology transfer goals for an implanted system because this electrode is currently Food and Drug Administration approved for diaphragm pacing in highlevel SCI patients [4]. 


\section{ACKNOWLEDGMENTS}

\section{Author Contributions:}

Study concept and design: J. S. Walter, D. Thomas.

Acquisition of data: J. S. Walter, D. Thomas, S. Sayers, S. Singh.

Analysis and interpretation of data: J. S. Walter, D. Thomas,

S. Sayers, S. Singh.

Drafting of manuscript: J. S. Walter, D. Thomas, R. A. Perez-Tamayo,

T. Crish, S. Singh.

Critical revision of manuscript for important intellectual content:

J. S. Walter, D. Thomas, S. Sayers, R. A. Perez-Tamayo, T. Crish,

S. Singh.

Statistical analysis: J. S. Walter.

Obtained funding: J. S. Walter.

Administrative, technical, or material support: J. S. Walter, S. Sayers, R. A. Perez-Tamayo, T. Crish.

Study supervision: J. S. Walter, D. Thomas.

Financial Disclosures: The authors have declared that no competing interests exist.

Funding/Support: This material was based on work supported by the Office of Research and Development, Rehabilitation Research and Development Service, Department of Veterans Affairs (grant B0348).

Additional Contributions: Support of Synapse Biomedical Inc by providing electrodes, stimulator, and technical assistance is gratefully appreciated. Experimental design discussions with Franco Laghi, MD, were appreciated.

Institutional Review: The Institutional Animal Studies Committee at the Edward Hines Jr., Department of Veterans Affair Hospital approved these animal study protocols.

\section{REFERENCES}

1. Laghi F, Tobin MJ. Disorders of the respiratory muscles. Am J Respir Crit Care Med. 2003;168(1):10-48. [PMID:12826594] http://dx.doi.org/10.1164/rccm.2206020

2. Loveridge BM, Dubo HI. Breathing pattern in chronic quadriplegia. Arch Phys Med Rehabil. 1990;71(7):495-99. [PMID:2350219]

3. Berlly M, Shem K. Respiratory management during the first five days after spinal cord injury. J Spinal Cord Med. 2007;30(4):309-18. [PMID:17853652]

4. Onders RP, Elmo M, Khansarinia S, Bowman B, Yee J, Road J, Bass B, Dunkin B, Ingvarsson PE, Oddsdóttir M. Complete worldwide operative experience in laparoscopic diaphragm pacing: Results and differences in spinal cord injured patients and amyotrophic lateral sclerosis patients. Surg Endosc. 2009;23(7):1433-40. [PMID:19067067] http://dx.doi.org/10.1007/s00464-008-0223-3

5. DiMarco AF, Supinski GS, Petro JA, Takaoka Y. Evaluation of intercostal pacing to provide artificial ventilation in quadriplegics. Am J Respir Crit Care Med. 1994;150(4):
934-40. [PMID:7921466]

http://dx.doi.org/10.1164/ajrccm.150.4.7921466

6. DiMarco AF, Kowalski KE, Geertman RT, Hromyak DR, Frost FS, Creasey GH, Nemunaitis GA. Lower thoracic spinal cord stimulation to restore cough in patients with spinal cord injury: results of a National Institutes of HealthSponsored clinical trial. Part II: clinical outcomes. Arch Phys Med Rehabil. 2009;90(5):726-32. [PMID:19406290] http://dx.doi.org/10.1016/j.apmr.2008.11.014

7. DiMarco AF, Takaoka Y, Kowalski KE. Combined intercostal and diaphragm pacing to provide artificial ventilation in patients with tetraplegia. Arch Phys Med Rehabil. 2005;86(6):1200-7. [PMID:15954060] http://dx.doi.org/10.1016/j.apmr.2004.11.027

8. DiMarco AF, Onders RP, Ignagni A, Kowalski KE, Mortimer JT. Phrenic nerve pacing via intramuscular diaphragm electrodes in tetraplegic subjects. Chest. 2005; 127(2):671-78. [PMID:15706014] http://dx.doi.org/10.1378/chest.127.2.671

9. DiMarco AF, Kowalski KE, Geertman RT, Hromyak DR. Spinal cord stimulation: A new method to produce an effective cough in patients with spinal cord injury. Am J Respir Crit Care Med. 2006;173(12):1386-89.

[PMID:16543552] http://dx.doi.org/10.1164/rccm.200601-097CR

10. Spivak E, Keren O, Niv D, Levental J, Steinberg F, Barak D, Chen B, Zupan A, Catz A. Electromyographic signalactivated functional electrical stimulation of abdominal muscles: The effect on pulmonary function in patients with tetraplegia. Spinal Cord. 2007;45(7):491-95.

[PMID:17325697]

http://dx.doi.org/10.1038/sj.sc.3102039

11. Lee BB, Boswell-Ruys C, Butler JE, Gandevia SC. Surface functional electrical stimulation of the abdominal muscles to enhance cough and assist tracheostomy decannulation after high-level spinal cord injury. J Spinal Cord Med. 2008;31(1):78-82. [PMID:18533416]

12. Lim J, Gorman RB, Saboisky JP, Gandevia SC, Butler JE. Optimal electrode placement for noninvasive electrical stimulation of human abdominal muscles. J Appl Physiol. 2007;102(4):1612-17. [PMID:17185493] http://dx.doi.org/10.1152/japplphysiol.00865.2006

13. Taylor PN, Tromans AM, Harris KR, Swain ID. Electrical stimulation of abdominal muscles for control of blood pressure and augmentation of cough in a C3/4 level tetraplegic. Spinal Cord. 2002;40(1):34-36. [PMID:11821968] http://dx.doi.org/10.1038/sj.sc.3101250

14. Hascakova-Bartova R, Dinant JF, Parent A, Ventura M. Neuromuscular electrical stimulation of completely paralyzed abdominal muscles in spinal cord-injured patients: A pilot study. Spinal Cord. 2008;46(6):445-50. 
JRRD, Volume 52, Number 1, 2015

[PMID:18227852]

http://dx.doi.org/10.1038/sj.sc.3102166

15. DiMarco AF, Romaniuk JR, Kowalski KE, Supinski GS. Efficacy of combined inspiratory intercostal and expiratory muscle pacing to maintain artificial ventilation. Am J Respir Crit Care Med. 1997;156(1):122-26.

[PMID:9230735] http://dx.doi.org/10.1164/ajrccm.156.1.9609103

16. DiMarco AF, Connors AF Jr, Kowalski KE. Gas exchange during separate diaphragm and intercostal muscle breathing. J Appl Physiol. 2004;96(6):2120-24. [PMID:15133014] http://dx.doi.org/10.1152/japplphysiol.00628.2003

17. DiMarco AF, Altose MD, Cropp A, Durand D. Activation of the inspiratory intercostal muscles by electrical stimulation of the spinal cord. Am Rev Respir Dis. 1987;136(6): 1385-90. [PMID:3688644] http://dx.doi.org/10.1164/ajrccm/136.6.1385

18. Lin V, Deng X, Xiong X, Lee Y, Sasee S, Hsiao I. Expiratory muscle activation using BION microstimulators in dogs. J Spinal Cord Med. 2000;28:370.

19. Dunn RB, Walter JS, Walsh J. Diaphragm and accessory respiratory muscle stimulation using intramuscular electrodes. Arch Phys Med Rehabil. 1995;76(3):266-71.

[PMID:7717821] http://dx.doi.org/10.1016/S0003-9993(95)80614-8

20. Walter JS, Dunn RB, Wurster RD, Laghi F. Microstimulators and intramuscular hook electrodes for the stimulation of respiratory muscles. J Spinal Cord Med. 2007;30(4): 338-45. [PMID:17853655]
21. Walter JS, Wurster RD, Zhu Q, Staunton C, Laghi F. Stimulating multiple respiratory muscles with intramuscular Permaloc electrodes. J Spinal Cord Med. 2010;33(2):135-43. [PMID:20486532]

22. Walter JS, Wurster RD, Zhu Q, Laghi F. Respiratory muscle pacing with chronically implanted intramuscular Permaloc electrodes: A feasibility study. J Rehabil Res Dev. 2011;48(2):103-14. [PMID:21480085] http://dx.doi.org/10.1682/JRRD.2010.05.0086

Submitted for publication January 24, 2014. Accepted in revised form November 19, 2014.

This article and any supplementary material should be cited as follows:

Walter JS, Thomas D, Sayers S, Perez-Tamayo RA, Crish T, Singh S. Respiratory responses to stimulation of abdominal and upper-thorax intercostal muscles using multiple Permaloc ${ }^{\circledR}$ electrodes. J Rehabil Res Dev. 2015; 52(1):85-96.

http://dx.doi.org/10.1682/JRRD.2014.01.0018

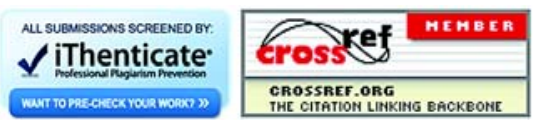

